\title{
On the compensation for illiquidity in sovereign credit markets
}

\author{
Jonatan Groba ${ }^{\mathrm{a}}$, Juan Angel Lafuente ${ }^{\mathrm{b}}$, Pedro Serrano ${ }^{\mathrm{c}}$ \\ ${ }^{a}$ Lancaster University Management School, Department of Accounting and Finance, Lancaster \\ LAI $4 Y X, U K$ \\ ${ }^{b}$ University Jaume I, Department of Finance and Accounting, Avda. Vicent Sos Baynat s/n, \\ E-12071 Castellón de la Plana, Spain \\ ${ }^{c}$ University Carlos III of Madrid, Department of Business Administration, C/ Madrid 126, 28903 \\ Getafe (Madrid), Spain
}

\begin{abstract}
This article analyzes the role of liquidity in the sovereign credit default swap (CDS) market. We employ a continuous-time specification to incorporate illiquidity as an additional pricing factor of default swap contracts for the most developed economies. The illiquidity discount process is identified as compensation to investors for the risk of unwinding their positions when trading in the less liquid part of the curve, and the information about illiquidity is directly extracted from the term structure of sovereign CDS spreads. Our empirical findings reveal that a positive time-varying illiquidity premium is embedded in sovereign default swaps. These risk premia exhibit substantial comovement across countries. Only unidirectional causality from default to liquidity is detected for the overall market.
\end{abstract}

*J. Groba acknowledges financial support from the Spanish Government project ECO201128134. J.A. Lafuente acknowledges financial support from the Ramon Areces Foundation, the Spanish Ministry of Education through grant ECO2012-31941, the Generalitat Valenciana through grant Prometeo II/2013/015 and the University Jaume I through grant P1.1A2012-09. P. Serrano acknowledges financial support from the Ministry of Economics and Competitiveness through grant ECO2012-34268. ${ }^{* *}$ Corresponding author. Tel: (+34)964387136; Fax: (+34)964728565

Email addresses: j.groba@lancaster.ac.uk (Jonatan Groba), lafuen@cofin.uji.es (Juan Angel Lafuente), pedrojose.serrano@uc3m.es (Pedro Serrano) 


\section{Introduction}

The financial market turmoil that started in August 2007 resulted in a sharp rise in borrowing costs, leading to a systematic increment in the prices of insurance against default (Dieckmann and Plank, 2012). Under those extreme market conditions, the liquidity of many credit instruments evaporated, and concerns about the existence of a market-wide liquidity risk factor being priced in credit markets have made room for related studies in the financial literature. Along these lines, the empirical evidence about the existence of a liquidity risk factor that is priced in the corporate bond markets is conclusive. A non-exhaustive review of this literature comprises the early work of Longstaff, Mithal and Neis (2005), who were pioneers in capturing the illiquidity discount in corporate bonds using default swap spreads as pure measures of default risk. Bao, Pan and Wang (2011) also find that bond illiquidity changes over time, exhibiting an important commonality in a cross-section of US corporate bonds, and Lin, Wang and Wu (2011) provide evidence that market-wide liquidity is priced in bond returns. In addition, De Jong and Driessen (2012) show a significant liquidity premium in a sample of corporate bond indexes of US bonds, being larger for lower-rated firms. More recently, Acharya, Amihud and Bharath (2013) show that liquidity risk becomes a significant determinant of US corporate bond returns, especially during financially stressed time periods, finding that the market price of liquidity is higher for non-investment grade bonds.

Although there is consensus on the importance of illiquidity shocks in corporate credit markets, fewer papers have examined the role of liquidity in sovereign credit markets under stressed circumstances. For instance, Beber, Brandt and Kavajecz (2009) and Arghyrou and Kontonikas (2012) find that during periods of market stress with large flows in the Euro-area bond market, liquidity explains a greater proportion of sovereign yield spreads than credit quality. There is also recent evidence that sovereign liquidity matters to institutions and institutional investors. Krishnamurthy and Vissing-Jorgensen (2012) document that decreases 
in Treasury supply raise the price of liquidity and drive down the yield on Treasuries relative to less liquid assets. Fontaine and Garcia (2012) study the role of financial intermediaries and find that funding liquidity is an important component of outstanding US Treasury bond returns, especially during crises. $\mathrm{Hu}, \mathrm{Pan}$ and Wang (2013) argue that abnormal noise in US Treasury prices is a symptom of shortage in arbitrage capital, and that this abnormal noise can be used as a proxy of illiquidity conditions of the overall market. A limited number of papers have suggested different liquidity effects at different maturities. Goyenko, Subrahmanyam and Ukhov (2011) note that during recessions the US Treasury market becomes more illiquid, and the increase in illiquidity is more pronounced for short-term maturities. Pan and Singleton (2008) indicate that illiquidity could be behind the idiosyncratic behavior of the short-term sovereign default swap maturities. Additionally, Bongaerts, Jong and Driessen (2011) suggest that unwinding a short-maturity CDS contract may be more costly than for a 5-year CDS. This preliminary evidence of different liquidity effects at different maturities motivates us to investigate whether there exists an illiquidity risk premium contained in the term structure of the CDS market to compensate those investors trading the most illiquid short-term contracts.

This paper studies the role of sovereign illiquidity risk, focusing on periods of financial distress. The information about default and liquidity is extracted from sovereign credit default swap (CDS) contracts, the preferred instrument of investors for shorting sovereign risk or speculating against the default of a country. CDSs are suitable tools for capturing the credit risk of the reference, as the informational content in default swap spreads leads stock and bond markets in terms of the price discovery process; see Blanco, Brennan and Marsh (2005) or Forte and Peña (2009). The sample comprises the full term structure of sovereign CDSs of main developed economies during the period from January 2006 to May 2013, covering the current financial crisis.

The modeling framework employed here builds on the spirit of Longstaff et al. 
(2005) and Arakelyan, Rubio and Serrano (2013), who identify the illiquidity discount process as the unexplained component in bonds and CDS prices, respectively. ${ }^{1}$ In particular, we closely follow Arakelyan et al. (2013) in analyzing the compensation to investors in corporate CDS portfolios for the risk of unwinding their positions when trading in the less liquid part of the curve - the maturities different from the 5-year CDS contract - . The information about the illiquidity discount is extracted from the short-term sovereign default swap spreads, in accordance with Pan and Singleton (2008), who consider the existence of an idiosyncratic liquidity factor in the CDS behavior at these maturities. We then estimate the illiquidity risk premium by using a continuous-time specification to model the dynamics of the risk-neutral illiquidity $\left(\gamma_{t}^{\mathbb{Q}}\right)$ and the arrival rate of default $\left(\lambda_{t}^{\mathbb{Q}}\right)$ discount processes of sovereign CDS contracts.

The main empirical findings in this paper can be summarized as follows. In addition to the default risk compensation in CDS prices reported by Pan and Singleton (2008) and Longstaff, Pan, Pedersen and Singleton (2011), we find a positive reward for investors trading in the illiquid part of the sovereign CDS curve. This illiquidity risk clearly affects the price of insurance against sovereign default, especially at short-term maturities. Moreover, the illiquidity premium is time-varying, and it dramatically increases during market-wide events such as the Lehman Brothers collapse or the European sovereign debt crisis. Second, the estimated illiquidity processes exhibit a significant comovement across countries, similarly to the commonality on sovereign default premia previously reported by Pan and Singleton (2008), Zinna (2013) or Groba, Lafuente and Serrano (2013). A principal component (PC) analysis on the illiquidity series shows that two components account for $56 \%$ of the total variance. The projections of these principal

\footnotetext{
${ }^{1}$ The literature on modeling the liquidity in credit markets by continuous-time processes was initiated by Longstaff et al. (2005) and Liu, Longstaff and Mandell (2006). This approach has been continued by, for example, Chen, Cheng and Wu (2013), Chen, Fabozzi and Sverdlove (2010), Bühler and Trapp (2009) and Lin, Liu and Wu (2009) within the context of CDS markets.
} 
components onto aggregate measures of market liquidity, such as bid-ask spreads, result in positive and statistically significant beta coefficients. These findings suggest the existence of a systematic illiquidity risk premium that is priced in the cross-section of sovereign CDS spreads.

Additionally, an inspection of the loadings of the first PC of the illiquidity premium shows that it is an equally-weighted contribution of individual sovereign CDS contracts. This first component might be interpreted as a rough estimate of aggregate illiquidity compensation. An analogous result is observed for the default risk premium. Then, we estimate a vector-autoregressive (VAR) model to delve into the dynamic relationship between aggregate illiquidity and default compensation. The null hypothesis that illiquidity causes (in the sense of Granger) default is empirically rejected. Notably, causality from default to illiquidity is not rejected by the Granger tests. These results are robust after controlling for stock market changes and liquidity proxies such as the bid-ask spreads.

Finally, our approach sheds light on the nature of certain systematic events during the recent financial crisis. According to our results, the collapse of Lehman Brothers on September 15th, 2008, resulted in a global systematic shock of illiquidity outside the US. In contrast, the effect detected inside the US was more important in terms of default compensation. Interestingly, it was the impact of the Euro crisis that led to a sharp rise in the compensation for liquidity in the US market.

The rest of the article is structured as follows: Section 2 introduces the model. Section 3 presents the sample and the econometric framework. Sections 4 and 5 analyze the illiquidity process and the illiquidity premia in sovereign CDS spreads, respectively. Finally, Section 6 concludes. 


\section{A two factor model for CDS prices}

\subsection{Model setup}

This paper adopts a continuous-time approach for extracting the illiquidity risk premium in sovereign CDS spreads. In this setting, default swaps are both pricing the default and the illiquidity risk of the reference entity. Then, the arrival of a default event $\left(\lambda_{t}^{\mathbb{Q}}\right)$ is modeled by a log Ornstein-Uhlenbeck (log-OU) process that, under the risk-neutral measure $\mathbb{Q}$, is expressed as,

$$
d \ln \lambda_{t}^{\mathbb{Q}}=\kappa_{1}^{\mathbb{Q}}\left(\theta_{1}^{\mathbb{Q}}-\ln \lambda_{t}^{\mathbb{Q}}\right) d t+\sigma_{1}^{\mathbb{Q}} d W_{1 t}^{\mathbb{Q}},
$$

with $\kappa_{1}^{\mathbb{Q}}$ the mean-reversion speed, $\theta_{1}^{\mathbb{Q}}$ the long-run mean, and $\sigma_{1}^{\mathbb{Q}}$ the volatility of the default. The variable $d W_{t}^{\mathbb{Q}}$ is a Brownian motion. The process $\lambda_{t}^{\mathbb{Q}}$ corresponds to the intensity of the Poisson process that triggers the credit event; see, among others, Duffie and Singleton (1997) and Lando (1998). Within the context of intensity models, the log-OU specification ensures the positiveness of the default process, as in Berndt, Douglas, Duffie, Ferguson and Schranz (2005), Pan and Singleton (2008) and Longstaff et al. (2011). Other modeling alternatives, such as Ornstein-Uhlenbeck and Cox, Ingersoll and Ross (CIR), have been discarded because of the extreme movements of default swap spreads during the crisis period. For example, the Feller condition in CIR processes limits the long-term mean of the intensity process to the square-root of its long-term variance, a fact that is frequently violated in credit spreads during the period 2007-2012.

The (risk-neutral) discount illiquidity process $\gamma_{t}^{\mathbb{Q}}$ is also modeled by a log-OU process,

$$
d \gamma_{t}^{\mathbb{Q}}=\kappa_{2}^{\mathbb{Q}}\left(\theta_{2}^{\mathbb{Q}}-\ln \gamma_{t}^{\mathbb{Q}}\right) d t+\sigma_{2}^{\mathbb{Q}} d W_{2 t}^{\mathbb{Q}}
$$

where $\kappa_{2}^{\mathbb{Q}}, \theta_{2}^{\mathbb{Q}}$ and $\sigma_{2}^{\mathbb{Q}}$ are the mean-reversion speed, the long-run mean, and the volatility of the illiquidity process, respectively. The $\gamma_{t}^{\mathbb{Q}}$ process reflects the risk- 
neutral illiquidity of CDS spreads, and it is extracted from the term-structure of CDS spreads using the prices from the most illiquid part of the CDS curve. ${ }^{2}$

Expressions (1) and (2) also admit a formulation under the historical measure $\mathbb{P}$ as follows,

$$
d \ln \lambda_{t}^{\mathbb{Q}}=\kappa_{1}^{\mathbb{P}}\left(\theta_{1}^{\mathbb{P}}-\ln \lambda_{t}^{\mathbb{Q}}\right) d t+\sigma_{1}^{\mathbb{Q}} d W_{1 t}^{\mathbb{P}},
$$

and,

$$
d \ln \gamma_{t}^{\mathbb{Q}}=\kappa_{2}^{\mathbb{P}}\left(\theta_{2}^{\mathbb{P}}-\ln \gamma_{t}^{\mathbb{Q}}\right) d t+\sigma_{2}^{\mathbb{Q}} d W_{2 t}^{\mathbb{P}},
$$

by applying the change of measure $d W_{t}^{\mathbb{Q}}=\Lambda_{t} d t+d W_{t}^{\mathbb{P}}$. The prices of risk of the default and illiquidity processes are, respectively, $\Lambda_{1 t}=\delta_{01}+\delta_{11} \ln \lambda_{t}^{\mathbb{Q}}$ and $\Lambda_{2 t}=\delta_{02}+\delta_{12} \ln \gamma_{t}^{\mathbb{Q}}$. Therefore, the relationship between parameters results in $\kappa_{i}^{\mathbb{P}} \theta_{i}^{\mathbb{P}}=\kappa_{i}^{\mathbb{Q}} \theta_{i}^{\mathbb{Q}}+\delta_{0 i} \sigma_{i}^{\mathbb{Q}}$ and $\kappa_{i}^{\mathbb{Q}}=\kappa_{i}^{\mathbb{P}}+\delta_{1 i} \sigma_{i}^{\mathbb{Q}}$, with $i=1,2$.

Our modeling proposal nests the specification of Pan and Singleton (2008) and Longstaff et al. (2011) by including the illiquidity as an additional factor on pricing the sovereign default swaps. A similar strategy has been previously proposed by Arakelyan et al. (2013) to capture the influence of illiquidity in credit-qualitysorted portfolios on corporate CDS spreads.

\subsection{The illiquidity risk premia}

When liquidity is heterogeneous across maturities, agents who look for arbitrage opportunities across the curve are also should require a compensation for closing their positions when needed (Arakelyan et al., 2013). Within the context of our model, the illiquidity risk premium accounts for the compensation due to

\footnotetext{
${ }^{2}$ Note that the illiquidity process is not modeled as a Poisson arrival. Some papers have modeled illiquidity in the same way as default events, suggesting that only the expected arrival of large illiquidity events matters in CDS pricing.
} 
changes in the trading ability of the CDS contract. We quantify the size of this illiquidity risk premium following the strategy in Pan and Singleton (2008) and Longstaff et al. (2011), which estimates the compensation of the default risk premium. ${ }^{3}$ We next describe how to derive the illiquidity risk premium.

In the absence of compensation for the uncertainty of changes in the default or liquidity environment, or zero risk-premium, equation (2) collapses to (4). Otherwise, the existence of a reward for changes in the risk factor conditions results in divergences between risk-neutral and (pseudo) actual measures. Let us consider the CDS spread under the risk-neutral measure,

$$
\operatorname{CDS}_{t}^{\mathbb{Q}}(M)=\frac{4\left(1-R^{\mathbb{Q}}\right) \int_{t}^{t+M} D(t, u) E_{t}^{\mathbb{Q}}\left[\lambda_{u}^{\mathbb{Q}} e^{-\int_{t}^{u}\left(\lambda_{s}^{\mathbb{Q}}+\gamma_{s}^{Q}\right) d s}\right] d u}{\sum_{i=1}^{4 M} D(t, t+j / 4) E_{t}^{\mathbb{Q}}\left[e^{-\int_{t}^{t+25 i}\left(\lambda_{s}^{\mathbb{Q}}+\gamma_{s}^{Q}\right) d s}\right]},
$$

where $M$ is the maturity of the $\operatorname{CDS}, D(\cdot)$ is the risk-free discount rate and $R^{\mathbb{Q}}$ is the risk-neutral recovery rate. Then, the illiquidity risk premium is defined as follows,

$$
R P_{i l l i q, t}=C D S_{t}^{\mathbb{Q}}-C D S_{i l l i q, t}^{\mathbb{P}}
$$

where $C D S_{\text {illiq,t }}^{\mathbb{P}}$ are called the pseudo-spreads and are expressed as

$$
C D S_{i l l i q, t}^{\mathbb{P}}(M)=\frac{4\left(1-R^{\mathbb{Q}}\right) \int_{t}^{t+M} D(t, u) E_{t}^{\mathbb{Q}}\left[\lambda_{u}^{\mathbb{Q}} e^{-\int_{t}^{u} \lambda_{s}^{\mathbb{Q}} d s}\right] E_{t}^{\mathbb{P}}\left[e^{-\int_{t}^{u} \gamma_{s}^{\mathbb{Q}} d s}\right] d u}{\sum_{i=1}^{4 M} D(t, t+j / 4) E_{t}^{\mathbb{Q}}\left[e^{-\int_{t}^{u} \lambda_{s}^{\mathbb{Q}} d s}\right] E_{t}^{\mathbb{P}}\left[e^{-\int_{t}^{u} \gamma_{s}^{\mathbb{Q}} d s}\right]}
$$

\footnotetext{
${ }^{3}$ Jarrow, Lando and Yu (2005) establish the risk premium framework in the intensity models, and they clearly distinguish between the distress risk premium, that is, compensation for changes in the fundamentals, and the default-event premium, or compensation for the changes in the price of the security in the event of default. Our formulation closely follows the literature on the default distress risk premium in Pan and Singleton (2008), Longstaff et al. (2011) and Zinna (2013), among others.
} 


\section{Econometric framework and results}

\subsection{The dataset}

Our dataset is composed of bi-weekly sovereign CDS spreads for seven countries belonging to the G8 group (United States, Japan, Germany, France, United Kingdom, Italy and Russia). Canada has been excluded because of data availability. We have at our disposal a full spectrum of maturities ranging from 1 to 10 years. The information about bid-ask spreads across all maturities is also available to us. The data comprise a maximum (minimum) of 192 (140) observations from January 2006 to May 2013, with the exception of the US and the UK, whose data start in January 2008. The contracts are denominated in dollars under the complete restructuring $(\mathrm{CR})$ clause. The dataset has been taken from CMA, a leading provider of CDS data.

To obtain a general overview of the sovereign market, a summary of the dataset is reported in Table 1. The US market, with more than $\$ 3$ billion of net amount outstanding, is the smallest contract. On the opposite side, the European countries are the most traded, partly due to the European sovereign debt difficulties during the last few years. Italy, at the center of the sovereign crisis, is the largest contract being traded, with $\$ 22.5$ billion that would be exchanged in the event of default if no recovery from the defaulted underlying bonds is due. Not surprisingly, the average CDS spread of Italy is over 100 basis points, as investors are worried about a likely default event in the near future.

\section{[TABLE 1 ABOUT HERE]}

Both Table 1 and Figure 1 highlight the differences in liquidity across maturities. Figure 1 depicts the absolute (upper graph) and relative (lower graph) cross-sectional average bid-ask spread for 1-, 5- and 10-year maturities involved in the analysis. Several conclusions arise from an inspection of Figure 1. First, the 1-year maturity contract exhibits, on average, a higher bid-ask spread in absolute and relative terms. This fact indicates that illiquidity risk may exhibit a 
short-run horizon, suggesting that an idiosyncratic liquidity factor is being priced into the one-year CDS contracts. A similar pattern is reported by Pan and Singleton (2008) for emerging economies. In contrast, the 5-year contract displays the lowest absolute and relative bid-ask spreads. Second, the effects of Lehman Brothers' collapse and the European sovereign debt crisis have resulted in systematic liquidity events. For example, the absolute bid-ask spreads peaked around those dates close to September 2008 (Lehman Brothers' default) and March 2012 (Greek sovereign debt restructure). Finally, the relative bid-ask spreads exhibit a downward trend during the sample period, increasing at the end.

\section{[FIGURE 1 ABOUT HERE]}

\subsection{Model estimation and results}

The parameters of the model in Section 2 are estimated by maximum likelihood (ML). Our methodology can be summarized in four steps. First, we assume that 1- and 5-year CDS spreads are perfectly priced. Additionally, the 5-year contract is assumed to be free of illiquidity frictions, so there is no significant illiquidity discount for this maturity. Then, we implicitly consider that maturities other than 5 years incorporate an illiquidity risk premium that compensates investors for trading alternative maturities to the most liquid contract. Second, we conjecture a time series of the $\lambda^{\mathbb{Q}}$ process by inversion of the pricing function of the 5-year CDS for a given set of parameters by means of a non-linear technique. Conditional on the $\lambda^{\mathbb{Q}}$ path, we also obtain a path for $\gamma^{\mathbb{Q}}$ by repeating this procedure on the 1-year contract. Both the $\lambda^{\mathbb{Q}}$ and $\gamma^{\mathbb{Q}}$ processes are employed subsequently for pricing the remaining default swaps.

In the step three, differences between the sample and theoretical remaining CDS contract maturities are priced with normally distributed errors $\epsilon_{M}$, with zero mean and standard deviation $\sigma_{M}$. We employ the bootstrapped USD Libor-Swap curve as a risk-free rate to discount future payoffs, as in Berndt et al. (2005). ${ }^{4}$

\footnotetext{
${ }^{4}$ The recent financial crisis raises some concerns about the standard proxies of the risk-free
} 
Then, we maximize the likelihood function

$$
\begin{aligned}
f^{\mathbb{P}}(\Theta, \lambda, \gamma) & =f^{\mathbb{P}}\left(\epsilon_{M} \mid \Theta, \lambda^{\mathbb{Q}}, \gamma^{\mathbb{Q}}\right) \times f_{A R}^{\mathbb{P}}\left(\ln \lambda^{\mathbb{Q}} \mid \Theta\right) \times\left|\partial C D S^{\mathbb{Q}}\left(\lambda^{\mathbb{Q}} \mid \Theta\right) / \partial \lambda^{\mathbb{Q}}\right|^{-1} \\
& \times f_{A R}^{\mathbb{P}}\left(\ln \gamma^{\mathbb{Q}} \mid \Theta, \lambda^{\mathbb{Q}}\right) \times\left|\partial C D S^{\mathbb{Q}}\left(\gamma^{\mathbb{Q}} \mid \Theta, \lambda^{\mathbb{Q}}\right) / \partial \gamma^{\mathbb{Q}}\right|^{-1}
\end{aligned}
$$

where $\Theta$ is the parameter vector $\Theta=\left(\kappa_{i}^{\mathbb{Q}}, \kappa_{i}^{\mathbb{Q}} \theta_{i}^{\mathbb{Q}}, \sigma_{i}^{\mathbb{Q}}, \kappa_{i}^{\mathbb{P}}, \kappa_{i}^{\mathbb{P}} \theta_{i}^{\mathbb{P}}, \sigma_{M}, R^{\mathbb{Q}}\right), i=1,2$, $f^{\mathbb{P}}(\cdot)$ is the density function of the Normal distribution, $f_{A R}^{\mathbb{P}}(\cdot)$ is the Gaussian density of an $\mathrm{AR}(1)$ process, and $\Delta t$ is equal to $1 / 26$. Finally, given that expectations of the $\log$-OU process in (5) and (7) are not in closed form, they are computed numerically using the Crank-Nicholson scheme.

Table 2 provides the ML estimates of the two-factor model under study. With regard to the default process, the mean-reversion rates $\left(\kappa_{1}^{\mathbb{Q}}\right)$ under the $\mathbb{Q}$ measure are systematically lower than their actual counterparts $\left(\kappa_{1}^{\mathbb{P}}\right)$. This result suggests an explosive behavior of the arrival of default events in the market CDS spreads. Additionally, the mean-arrival rates of credit events under the risk-neutral measure are higher than under the actual one $\left(\kappa_{1}^{\mathbb{Q}} \theta_{1}^{\mathbb{Q}}>\kappa_{1}^{\mathbb{P}} \theta_{1}^{\mathbb{P}}\right)$, which results in an arrival of credit events much more intense in the risk-neutral than the actual world. In other words, the risk-neutral environment worsens over time (the arrival of credit events increases) with respect to the actual intensity. These results are consistent with those previously obtained by Pan and Singleton (2008), where a systematic default risk premium is being priced in the sovereign CDS spreads of three emerging economies.

rate curve. Lando (2004) and references therein discuss the role of the swap curve, concluding that this curve is the standard risk-free curve for pricing longer maturities. Longstaff et al. (2011) demonstrate the robustness of their model estimates to the discounting curve employed. They argue that moving from the swap curve to the Treasury curve for discounting future clash-flows has no effect on the price of the default swap because the discounting curve is applied symmetrically to both sides of the contract. Therefore, the swap curve is considered by the market as riskless despite its limitations. In any case, the literature does not seem to provide a clear alternative to our measure. This article employs the 3-, 6-, 9- and 12-month USD Libor that is published by the British Bankers'Association and the 2-, 3-, 4-, 5-, 7- and 10-year USD interest rate swaps from the Federal Reserve Statistical Release H.15. 
[TABLE 2 ABOUT HERE]

The point estimates for parameters related to the illiquidity process reveal some interesting aspects. Table 2 suggests that a positive illiquidity risk premium is priced in the sovereign CDS market. It is also observed that the mean-reversion rates are higher under actual than risk-neutral measures $\left(\kappa_{2}^{\mathbb{P}}>\kappa_{2}^{\mathbb{Q}}\right)$, revealing that an explosive behavior of the illiquidity discount process is implied in the market spreads. However, the long-term mean of the process is much more intense in the risk-neutral than the actual environment $\left(\kappa_{2}^{\mathbb{Q}} \theta_{2}^{\mathbb{Q}}>\kappa_{2}^{\mathbb{P}} \theta_{2}^{\mathbb{P}}\right)$. Such a size disparity in mean-reversion and long-run parameters under both measures indicates that, although a low discount process of illiquidity is considered in the actual world, the risk-neutral scenario is significantly stressed. These facts are consistent with a systematic departure of risk-neutral from real intensities that diverge as time goes by. This fact is also corroborated by the systematic negative signs of $\delta_{02}$ and $\delta_{12}$. To put it another way, CDS investors demand a higher risk premium for trading an illiquid contract with respect to the 5-year benchmark.

Another interesting result in Table 2 concerns the fluctuations of the discount processes. A comparison of the ML estimates shows that the illiquidity discount volatility is significantly higher than the default volatility $\left(\sigma_{2}^{\mathbb{Q}}>\sigma_{1}^{\mathbb{Q}}\right)$. This result is independent of the economy under analysis, and it suggests that liquidity shocks tend to exhibit a higher uncertainty than the default shocks. These findings seem to indicate a more strained environment in the illiquidity factor.

The volatility of the mispricing errors $\left(\sigma_{M}\right)$ is 15 basis points (bps) on average. Measurement errors are negligible in terms of the level of CDS spread, suggesting a good performance of the model. Finally, the point estimates for the implied risk-neutral recovery rates $\left(R^{\mathbb{Q}}\right)$ indicate a classification of the economies into three different groups, according to their degree of creditworthiness implied by the market: high (Germany and UK); medium (US, Japan, France and Italy); and low (Russia). 


\section{Liquidity patterns in the sovereign CDS market}

After quantifying the market compensation to investors for illiquidity and default risk, this section analyzes their potential sources of variability using financial and macroeconomic information.

\subsection{The discount processes}

Figure 2 depicts the time evolution of the risk-neutral default $\left(\lambda^{\mathbb{Q}}\right)$ and illiquidity $\left(\gamma^{\mathbb{Q}}\right)$ discount processes. For ease of explanation, this Figure also includes some relevant economic events during the period under analysis. Some interesting features can be observed in Figure 2. The default intensity is time-varying, and it spikes on financially distressed moments such as the collapse of Lehman Brothers. This event led to a worldwide shock in the default level that spread to the remaining developed economies. The default discount is much more intense for Russia and Italy, and Japan and the US exhibit the lowest default intensities. The Figure also shows a rise in the market default probabilities for the European Monetary Union (EMU) core countries: Germany and France. These countries show a significant commonality in the default processes, possibly as a reaction to the Greek crisis that began in March 2010.

\section{[FIGURE 2 ABOUT HERE]}

In general, illiquidity shocks are linked to a stressed environment. It seems that illiquidity problems appear when the default conditions erode. Furthermore, the dynamics of the illiquidity processes are less persistent than those of the default one. Illiquidity exhibits a stronger mean-reversion pattern than default does, suggesting that illiquidity crises are short-lived episodes. For example, this pattern is clearly observable for Japan, the UK and Russia after the collapse of Lehman Brothers and for the EMU countries during the sovereign debt crisis. While the illiquidity discount is lower than the default discount in general, the illiquidity discount can dominate the default one during some distressed episodes, as seen for the US, Japan and France. 


\subsection{The compensation for illiquidity}

Figure 3 plots the compensation for illiquidity (right axis) and default (left axis) risks. This Figure solely focuses on the results for the 1-year CDS maturity; recall that the 5-year default swap does not contain a liquidity premium by assumption. Figure 3 shows that, in addition to a default risk premium, an illiquidity risk premium is being priced in the sovereign CDS market. This compensation for illiquidity also varies substantially over time and, as expected, it is significantly affected by the collapse of Lehman Brothers, especially in the case of Russia. The illiquidity premium tends to be relatively more important than the default premium under financial distress. This is the case of Japan during the Lehman Brothers' default and of the EMU countries - Germany, France and Italy - during the European sovereign debt crisis.

Illiquidity premia are heterogeneous across countries: the US and the UK exhibit a significantly lower reward for illiquidity than the other economies. In accordance with the pattern described for the discount processes, the illiquidity risk premium exhibits a higher mean reversion pattern than the default premium; the sovereign CDS market appears to accommodate liquidity shocks in a short period of time.

\section{[FIGURE 3 ABOUT HERE]}

To examine whether illiquidity risk is country-specific or driven by global factors, we study the principal component structure of the (standardized) illiquidity and default risk premia time series. Table 3 summarizes this information. The first principal component (PC) accounts for approximately $37 \%$ of the total explained variance of the illiquidity premia series. Relative to default, the variability explained is higher and reaches $56 \%$ of the default premia. These values reflect the existence of strong commonalities for either the illiquidity or default risk premia across countries. With the exception of the US, all the economies have associated non-negligible loadings for the first principal component of illiquidity. This 
feature suggests that while liquidity stress conditions tend to disseminate in the Euro-area, Japan and Russia in a similar way, the US economy has a specific component in the time evolution of illiquidity risk premia.

\section{[TABLE 3 ABOUT HERE]}

The second PC also gathers an important portion of the total variance. The total explained variance increases up to $57 \%$ and $85 \%$ for the illiquidity and default processes, respectively. This result indicates that illiquidity exhibits a more idiosyncratic nature than default does. As to illiquidity, the loadings corresponding to the second PCs for the US, Germany, France and Italy are positive, while they are negative for the rest of the countries in the sample. This second PC could be interpreted as a spread between countries being affected more intensively by the financial crisis and the rest of the countries.

\subsection{On the relationship between the illiquidity risk and economic variables}

Previous results suggest the existence of systematic risks priced in sovereign CDS contracts. Given the evidence of strong commonality in sovereign risk premia, the next step is to explore the possible economic factors behind these risks. To identify these possible sources of risk, we project the illiquidity and default risk premia onto a set of key financial market variables. In particular, we structure our analysis according to four major areas: liquidity, stock market, currency markets, and bond market. ${ }^{5}$

First, we examine the connection between illiquidity and default risk premia with traditional measures of illiquidity in the CDS market. In this regard, we construct the first principal components of the 1-year bid-ask spreads and the net

\footnotetext{
${ }^{5}$ Although the list of possible regressor candidates is huge, we mainly employ financial market variables because they aggregate an important part of the available information in the economy (Longstaff et al., 2011). Along these lines, we employ the first principal components of the financial variables because these components gather the major portion of the joint variability.
} 
outstanding volume of the default swaps to capture the overall illiquidity in the CDS market. The bid-ask spread represents the spread earned by market makers acting as intermediaries and holding zero-net positions in the CDS market, see Bongaerts et al. (2011). The net volume represents the liquidity risk and is defined as the agreed maximum possible net funds transfers between net sellers and net buyers of protection that would be exchanged after a credit event (Tang and Yan, 2007).

Second, to capture the global state of the economy, we use financial variables commonly employed in related papers of CDS analysis, such as those of CollinDufresne, Goldstein and Martin (2001), Ericsson, Jacobs and Oviedo (2009) and Dieckmann and Plank (2012). Given the importance of the equity market, it is worth studying how this market relates to our measures of illiquidity and default premia. To reflect the variation in the equity markets we employ the first principal component of the different local stock markets (DAX, FTSE 100, NIKKEI 225, RTS, S\&P 500, CAC 40, and FTSE MIB). Another important factor in the stock market is the volatility premium; see Longstaff et al. (2011). Thus, we also include the volatility premium of the US economy using the difference between the VIX index - an option-implied volatility index - and the Garman and Klass (1980) volatility estimator. Third, regarding the currency market, we include the first principal component of the exchange rates of the US dollar against the corresponding national currency (Japanese Yen, Euro, Pound Sterling, and Russian Ruble). Fourth, to account for the conditions of the corporate bond market, we include the difference between the Moody's Baa and Aaa Corporate Bond Yield Indexes.

Table 4 reports the OLS estimates for the increments in the first principal components ( $\mathrm{PC} 1$ and $\mathrm{PC} 2$ ) from the illiquidity and default risk premia against the increments in our set of financial variables. Focusing on the illiquidity premia from the countries in our sample, the first component exhibits a positive and a highly statistically significant beta with the 1-year bid-ask spreads. In other 
words, positive increments in market makers' earnings are linked to increments of the illiquidity premium. Interestingly, the behavior of the stock market returns is negatively correlated with the illiquidity's first PC, suggesting that negative global news about dividends and stock returns are also priced in the sovereign CDS market via an illiquidity channel. The adjusted- $R^{2}$ of the regression, with bid-ask and stock market as the main drivers, reaches $20 \%$.

With regard to the second PC of the illiquidity premia, we find a significant (and positive) relation with the bid-ask spread and the net notional volume of CDS, both traditional liquidity measures of the CDS market. Recall that the second PC of the illiquidity could be interpreted as a spread between countries being affected more intensively by the financial crisis (France, Germany, Italy and US) and the rest. Interestingly, the countries most affected by the crisis are the most traded, and together they represent $74 \%$ of the total net outstanding CDS volume. Therefore, this second component seems be exclusively related to market-wide liquidity risk in countries affected by the financial crisis.

\section{[TABLE 4 ABOUT HERE]}

Concerning the default risk, Table 4 shows that the default premium betas of first PC are statistically significant for bid-ask spreads, stock market, volatility premium and currency markets. The aggregate bid-ask spread covariates positively with the first component of default risk, reflecting that increments of aggregate default risk are linked to increments of the market illiquidity measured by bid-ask spreads. In contrast, the associated betas for stock, volatility and currency variables are negative and significant at the $1 \%$ confidence level. The economic interpretation is that a decline in the aggregate stock market, volatility premium or exchange rate results in increments of the aggregate default risk compensation. These results are broadly consistent with previous findings in the related literature. Collin-Dufresne et al. (2001), Ericsson et al. (2009), Longstaff et al. (2011) and Dieckmann and Plank (2012) show that the stock index has a negative impact 
on corporate and sovereign credit spreads. Longstaff et al. (2011) find a negative relation between the volatility premium and the default risk premium. Longstaff et al. (2011) and Dieckmann and Plank (2012) find that a depreciation of the currencies against the dollar increases the sovereign default swap spreads. Hilscher and Nosbusch (2010) and Dieckmann and Plank (2012) do not find strong evidence that the default yield spread between Baa- and Aaa-rated corporate debt affects sovereign credit spreads.

The explanatory power of the model is also remarkable, as reflected by an adjusted- $R^{2}$ that exceeds $45 \%$. Surprisingly, bid-ask spreads is the only significant variable in explaining the second PC of default premia. The loadings in the second component of default premia distinguish between the group composed of the US, the UK and Russia and the group containing the rest. The strong relation between bid-ask spreads and the default premia is in line with the findings of Bongaerts et al. (2011), where these authors show that bid-ask spreads and CDS spreads are positively related. Consistent with an increasing globalization of the world's economies in recent years, these results suggest that overall illiquidity and default market conditions are closely related across countries.

In sum, our results show that the illiquidity discount processes exhibit a strong mean-reversion pattern. Illiquidity crises are linked to stressed periods, and a positive illiquidity risk premium seems to be priced in the sovereign CDS market. This illiquidity premium exhibits a notable degree of commonality, and two principal components capture approximately $57 \%$ of the total variance. These components covariate positively with aggregate illiquidity variables such as the bid-ask spread and net outstanding CDS volumes. Moreover, the aggregate stock market risk seems to be relevant for explaining the variability of the illiquidity risk premium. 


\section{The relationship between aggregate illiquidity and aggregate default risk premia}

Previous empirical findings place us in a privileged position to analyze the joint dynamics of illiquidity and default risk in the credit derivatives market. This section delves into the link between illiquidity and default risk compensation. To this end, we consider the information embedded in the first principal components of illiquidity (ILLIQ) and default ( $D E F)$ risk premia computed in Section 3. The use of these principal components in our analysis provides interesting advantages. For instance, the loading coefficients of the first principal components are nearly equal. Moreover, the ILLIQ and $D E F$ variables account for an important fraction of the joint variability of the sample, making these variables into potential proxies of aggregate illiquidity and aggregate default risk premia.

To explore the joint dynamics of $I L L I Q$ and $D E F$, we use a vector autoregressive (VAR) model. As a first step in our analysis, we run a bivariate VAR, a parsimonious representation of the methodology. Table 5 reports the Granger causality tests. ${ }^{6}$ Panel A shows the chi-square statistics for the first model. The tests show that the illiquidity premium does not precede the default compensation. In contrast, this default compensation seems to bring information into the illiquidity premium.

\section{[TABLE 5 ABOUT HERE]}

As a second step, we enlarge the model specification by including additional information from financial variables such as the stock market $(S T O C K)$ and the bid-ask spread (BIDAS $K$ ). These variables were previously identified as potential variables of interest in the analysis in Table 4. Then, we run a four-variable VAR that comprises illiquidity $(I L L I Q)$, default $(D E F)$, stock market and bid-ask

\footnotetext{
${ }^{6}$ For the sake of exposition, the model coefficient estimates and their significance are not displayed but are available upon request.
} 
spread. Panel B of Table 5 reports the causality tests for these four variables. The presence of the stock market and the bid-ask spreads significantly reduces the direct effect of the default premium on the illiquidity premium. The variable ILLIQ does not precede DEF.

These previous results seem to be consistent with the idea that default is a driver of illiquidity in the CDS market. To further examine this idea, Figure 4 depicts the impulse-response figures for the bivariate (Panel A) and the four variable (Panel B) models. On the one hand, Panel A reveals a strong positive increase in the illiquidity compensation as a response to a shock in the default risk compensation (left graph). This shock lasts at least 10 weeks. In contrast, the response in default to a shock in illiquidity is not statistically significant (right graph). On the other hand, Panel B shows an insignificant response in the illiquidity compensation after a shock in the default compensation when we include the stock market and the bid-ask spreads in the VAR model. More interestingly, we find that the largest response in the illiquidity compensation comes after a shock in the stock market.

\section{[FIGURE 4 ABOUT HERE]}

A closer look at the importance of the stock and bid-ask spread variables in the illiquidity risk premium is provided in Table 6, which presents the variance decomposition of the illiquidity premium variable. This table reports the percentage of variation in ILLIQ as a result of a shock in $S T O C K, D E F, B I D A S K$, and $I L L I Q$. Each row must sum to one because the sum represents the total variation in $I L L I Q$. The largest response of $I L L I Q$ in the first two weeks $(78.91 \%)$ following the shocks is due to its own shock. However, the effect of this shock declines smoothly. The decomposition reveals that most of the variability in the illiquidity comes from new information arriving for the stock market and the bid-ask spread. For example, the percentage of variation of the illiquidity due to changes in the bid-ask spread is $12.80 \%$ after eight weeks. A shock to the stock market initially 
has a small impact, but after the first few weeks, the importance of the variable increases, accounting for $21.20 \%$ of the variability in the long-run. Therefore, only the bid-ask spread and the stock market seem to be important in explaining illiquidity prices. The default premium does not represent an important fraction of the total variability. Again, this result suggests that the relationship obtained in the bivariate VAR model is due to other sources of information affecting the CDS market and not to a direct effect of the default premium on the illiquidity premium.

\section{[TABLE 6 ABOUT HERE]}

This relation between our aggregate illiquidity premium and the other market prices is instructive, as it highlights the important fact that illiquidity prices in the credit market are a result of unexpected events affecting the financial markets overall. Illiquidity compensation is not just a result of events affecting only sovereign credit market participants. In particular, our results show that the stock market is rather informative about the liquidity prices in the CDS market. We find that the stock market reversals seem to convey information into illiquidity prices that may last up to half a year.

\section{Conclusions}

This paper studies the existence of a compensation for illiquidity in sovereign credit markets. Using the information content in the term structure of the credit default swap spreads, we estimate a continuous time two-factor model that uncovers the risk-neutral illiquidity $\left(\gamma^{Q}\right)$ and default $\left(\lambda^{Q}\right)$ discount processes from CDS prices. The maximum likelihood estimates of the model show that the discount illiquidity process presents a stronger mean-reversion pattern than the default discount. Moreover, illiquidity-distressed episodes are short-lasting. 
Our results also suggest that a positive illiquidity risk premium is being priced in the sovereign CDS market. This illiquidity premium is related to the risk of unwinding the positions in short-term contracts, and it can exceed the default compensation during the stressed periods. The illiquidity premia also exhibit a notable degree of commonality: two principal components capture approximately $57 \%$ of the total variance. These principal components covariate with aggregate illiquidity variables such as the bid-ask spread and net volumes, and the estimated correlations are positive and statistically significant. These results suggest that a relevant portion of information about the aggregate illiquidity risk in the CDS market could be priced in the default swap curve and, indeed, can be captured by our illiquidity premium. In addition, the stock market is also significant in explaining the variability of the illiquidity risk premium.

We also develop a vector autoregressive (VAR) analysis on the illiquidity and default first components to inspect their dynamics. The Granger causality tests show that shocks in the aggregate default compensation have a positive impact on the aggregate liquidity premium. However, the causality in the opposite direction is rejected at conventional significant levels. Therefore, changes in the illiquidity compensation could appear as a result of a shock affecting default. This pattern of causality disappears after controlling for bid-ask spreads and stock market changes, suggesting that there is no direct effect of default premium on the illiquidity premium.

Our empirical findings could contribute to the current debate on the role of liquidity in credit derivative markets. The systematic nature of illiquidity shocks enhances the advantages of a coordinated trading system to improve pricing efficiency, to favor credit risk hedging during distressed market conditions, and to make CDS trading less vulnerable to liquidity droughts. 


\section{References}

Acharya, V.V., Amihud, Y., Bharath, S.T., 2013. Liquidity risk of corporate bond returns: A conditional approach. Journal of Financial Economics 110, 358-386.

Arakelyan, A., Rubio, G., Serrano, P., 2013. Market-wide liquidity in credit default swap spreads. Working Paper.

Arghyrou, M.G., Kontonikas, A., 2012. The EMU sovereign-debt crisis: Fundamentals, expectations and contagion. Journal of International Financial Markets, Institutions \& Money 22, 658-677.

Bao, J., Pan, J., Wang, J., 2011. The illiquidity of corporate bonds. The Journal of Finance 66, 911-946.

Beber, A., Brandt, M.W., Kavajecz, K.A., 2009. Flight-to-quality or flight-toliquidity? Evidence from the euro-area bond market. The Review of Financial Studies 22, 925-957.

Berndt, A., Douglas, R., Duffie, D., Ferguson, M., Schranz, D., 2005. Measuring default risk premia from default swap rates and EDFs. Working Paper.

Blanco, R., Brennan, S., Marsh, I.W., 2005. An empirical analysis of the dynamic relation between investment-grade bonds and credit default swaps. The Journal of Finance 60, 2255-2281.

Bongaerts, D., Jong, F.D., Driessen, J., 2011. Derivative pricing with liquidity risk: theory and evidence from the credit default swap market. The Journal of Finance 66, 203-240.

Bühler, W., Trapp, M., 2009. Time-varying credit risk and liquidity premia in bond and CDS markets. Working Paper. 
Chen, R.R., Cheng, X., Wu, L., 2013. Dynamic interactions between interest-rate and credit risk: Theory and evidence on the credit default swap term structure. Review of Finance 17, 403-441.

Chen, R.R., Fabozzi, F.J., Sverdlove, R., 2010. Corporate credit default swap liquidity and its implications for corporate bond spreads. The Journal of Fixed Income 20, 31-57.

Collin-Dufresne, P., Goldstein, R.S., Martin, J.S., 2001. The determinants of credit spread changes. The Journal of Finance 56, 2177-2207.

De Jong, F., Driessen, J., 2012. Liquidity risk premia in corporate bond markets. Quarterly Journal of Finance 02.

Dieckmann, S., Plank, T., 2012. Default risk of advanced economies: An empirical analysis of credit default swaps during the financial crisis. Review of Finance 16, 902-934.

Duffie, D., Singleton, K.J., 1997. An econometric model of the term structure of interest-rate swap yields. The Journal of Finance 52, 1287-1321.

Ericsson, J., Jacobs, K., Oviedo, R., 2009. The determinants of credit default swap premia. Journal of Financial and Quantitative Analysis 44, 109-132.

Fontaine, J.S., Garcia, R., 2012. Bond liquidity premia. The Review of Financial Studies 25, 1207-1254.

Forte, S., Peña, J.I., 2009. Credit spreads: An empirical analysis on the informational content of stocks, bonds, and CDS. Journal of Banking \& Finance 33, 2013-2025.

Garman, M.B., Klass, M.J., 1980. On the estimation of security price volatilities from historical data. The Journal of Business 53, 67-78. 
Goyenko, R., Subrahmanyam, A., Ukhov, A., 2011. The term structure of bond market liquidity and its implications for expected bond returns. Journal of Financial and Quantitative Analysis 46, 111-139.

Groba, J., Lafuente, J.A., Serrano, P., 2013. The impact of distressed economies on the EU sovereign market. Journal of Banking \& Finance 37, 2520-2532.

Hilscher, J., Nosbusch, Y., 2010. Determinants of sovereign risk: Macroeconomic fundamentals and the pricing of sovereign debt. Review of Finance 14, 1-28.

Hu, G.X., Pan, J., Wang, J., 2013. Noise as information for illiquidity. The Journal of Finance 68, 2341-2382.

Jarrow, R.A., Lando, D., Yu, F., 2005. Default risk and diversification: Theory and empirical implications. Mathematical Finance 15, 1-26.

Krishnamurthy, A., Vissing-Jorgensen, A., 2012. The aggregate demand for treasury debt. Journal of Political Economy 120, 233-267.

Lando, D., 1998. On Cox processes and credit risky securities. Review of Derivatives Research 2, 99-120.

Lando, D., 2004. Credit Risk Modeling: Theory and Applications. Princeton University Press.

Lin, H., Liu, S., Wu, C., 2009. Liquidity premia in the credit default swap and corporate bond markets. Working Paper.

Lin, H., Wang, J., Wu, C., 2011. Liquidity risk and expected corporate bond returns. Journal of Financial Economics 99, 628-650.

Liu, J., Longstaff, F.A., Mandell, R.E., 2006. The market price of risk in interest rate swaps: the roles of default and liquidity risks. Journal of Business 79, 2337-2359. 
Longstaff, F.A., Mithal, S., Neis, E., 2005. Corporate yield spreads: Default risk or liquidity? New evidence from the credit default swap market. The Journal of Finance 60, 2213-2253.

Longstaff, F.A., Pan, J., Pedersen, L.H., Singleton, K.J., 2011. How sovereign is sovereign credit risk? American Economic Journal: Macroeconomics 3, $75-103$.

Pan, J.U.N., Singleton, K.J., 2008. Default and recovery implicit in the term structure of sovereign CDS spreads. The Journal of Finance 63, 2345-2384.

Tang, D.Y., Yan, H., 2007. Liquidity and credit default swap spreads. Working Paper.

Zinna, G., 2013. Sovereign default risk premia: Evidence from the default swap market. Journal of Empirical Finance 21, 15-35. 
Table 1: Average market size and price by country

\begin{tabular}{lrrrrr}
\hline & $\begin{array}{r}\text { Net volume } \\
\text { (billion USD) }\end{array}$ & $\begin{array}{r}\text { CDS1y } \\
(\mathrm{bps})\end{array}$ & $\begin{array}{r}\text { CDS5y } \\
(\mathrm{bps})\end{array}$ & $\begin{array}{r}\text { Bid-Ask1y } \\
(\mathrm{bps})\end{array}$ & $\begin{array}{r}\text { Bid-Ask5y } \\
(\mathrm{bps})\end{array}$ \\
\cline { 2 - 6 } France & & & & & \\
Germany & 15.1 & 27.68 & 60.37 & 3.53 & 3.06 \\
Italy & 15.1 & 13.45 & 33.55 & 2.71 & 2.64 \\
Japan & 22.5 & 107.65 & 156.22 & 10.88 & 4.75 \\
Russia & 6.49 & 18.64 & 52.86 & 3.85 & 3.82 \\
UK & 4.81 & 125.82 & 180.93 & 14.04 & 4.57 \\
US & 8.54 & 29.06 & 62.54 & 4.79 & 4.19 \\
\hline
\end{tabular}

The CDS prices and Bid-Ask spreads are obtained from CMA through Thomson Reuters Datastream. The Net Volume Outstanding is obtained from The Depository Trust \& Clearing Corporation (DTCC). The sample period covers January 2006 to May 2013, and the data frequency is bi-weekly. 
Table 2: Maximum likelihood model parameters

\begin{tabular}{|c|c|c|c|c|c|c|c|}
\hline \multirow[b]{2}{*}{ Parameters } & \multicolumn{7}{|c|}{ Countries } \\
\hline & US & Japan & Germany & France & UK & Italy & Russia \\
\hline$\kappa_{1}^{\mathbb{Q}}$ & $\begin{array}{c}0.4275 \\
(0.0865)\end{array}$ & $\begin{array}{c}0.2088 \\
(0.0342)\end{array}$ & $\begin{array}{l}-0.7022 \\
(0.1489)\end{array}$ & $\begin{array}{c}0.3913 \\
(0.1517)\end{array}$ & $\begin{array}{l}-1.9265 \\
(0.2295)\end{array}$ & $\begin{array}{c}0.0286 \\
(0.0360)\end{array}$ & $\begin{array}{c}0.2603 \\
(0.0228)\end{array}$ \\
\hline$\kappa_{1}^{\mathbb{Q}} \theta_{1}^{\mathbb{Q}}$ & $\begin{array}{l}-2.8246 \\
(0.6241)\end{array}$ & $\begin{array}{l}-1.1918 \\
(0.2837)\end{array}$ & $\begin{array}{c}3.2654 \\
(0.6577)\end{array}$ & $\begin{array}{l}-2.2515 \\
(1.1100)\end{array}$ & $\begin{array}{l}12.9776 \\
(1.1017)\end{array}$ & $\begin{array}{l}-0.2119 \\
(0.2370)\end{array}$ & $\begin{array}{l}-1.1763 \\
(0.0803)\end{array}$ \\
\hline$\sigma_{1}^{\mathbb{Q}}$ & $\begin{array}{c}1.8865 \\
(0.1550)\end{array}$ & $\begin{array}{c}1.8833 \\
(0.1700)\end{array}$ & $\begin{array}{c}0.7870 \\
(0.1075)\end{array}$ & $\begin{array}{c}2.3753 \\
(0.1907)\end{array}$ & $\begin{array}{c}2.6297 \\
(0.2511)\end{array}$ & $\begin{array}{c}1.0052 \\
(0.0660)\end{array}$ & $\begin{array}{c}0.9995 \\
(0.1364)\end{array}$ \\
\hline$\kappa_{1}^{\mathbb{P}}$ & $\begin{array}{c}2.2354 \\
(1.3713)\end{array}$ & $\begin{array}{c}2.3093 \\
(1.2724)\end{array}$ & $\begin{array}{c}0.5399 \\
(0.6261)\end{array}$ & $\begin{array}{c}0.8503 \\
(1.6694)\end{array}$ & $\begin{array}{c}1.8554 \\
(1.4915)\end{array}$ & $\begin{array}{c}0.2193 \\
(0.2928)\end{array}$ & $\begin{array}{c}0.8024 \\
(0.2371)\end{array}$ \\
\hline$\kappa_{1}^{\mathbb{P}} \theta_{1}^{\mathbb{P}}$ & $\begin{array}{c}-15.2733 \\
(9.2364)\end{array}$ & $\begin{array}{c}-17.4990 \\
(9.1227)\end{array}$ & $\begin{array}{l}-2.6678 \\
(2.8634)\end{array}$ & $\begin{array}{c}-6.5940 \\
(11.2957)\end{array}$ & $\begin{array}{c}-11.7592 \\
(8.0996)\end{array}$ & $\begin{array}{c}-1.0977 \\
(1.3298)\end{array}$ & $\begin{array}{l}-4.2585 \\
(1.2282)\end{array}$ \\
\hline$\kappa_{2}^{\mathbb{Q}}$ & $\begin{array}{c}2.5157 \\
(0.2141)\end{array}$ & $\begin{array}{c}1.0000 \\
(0.0893)\end{array}$ & $\begin{array}{l}-0.8336 \\
(0.2374)\end{array}$ & $\begin{array}{c}1.0000 \\
(0.1249)\end{array}$ & $\begin{array}{l}-1.7852 \\
(0.2985)\end{array}$ & $\begin{array}{l}-0.1563 \\
(0.0800)\end{array}$ & $\begin{array}{c}0.6562 \\
(0.0687)\end{array}$ \\
\hline$\kappa_{2}^{\mathbb{Q}} \theta_{2}^{\mathbb{Q}}$ & $\begin{array}{c}-30.0000 \\
(3.5732)\end{array}$ & $\begin{array}{c}-26.0000 \\
(1.6493)\end{array}$ & $\begin{array}{l}-1.5765 \\
(1.0868)\end{array}$ & $\begin{array}{c}-26.0000 \\
(6.1683)\end{array}$ & $\begin{array}{c}2.4209 \\
(0.6246)\end{array}$ & $\begin{array}{l}-29.9531 \\
(30.0538)\end{array}$ & $\begin{array}{l}-29.0000 \\
(12.9901)\end{array}$ \\
\hline$\sigma_{2}^{\mathbb{Q}}$ & $\begin{array}{c}5.9688 \\
(0.5745)\end{array}$ & $\begin{array}{c}7.7471 \\
(0.4570)\end{array}$ & $\begin{array}{c}6.0444 \\
(0.2287)\end{array}$ & $\begin{array}{c}7.7920 \\
(0.9832)\end{array}$ & $\begin{array}{c}8.2834 \\
(0.6674)\end{array}$ & $\begin{array}{l}13.0352 \\
(5.6994)\end{array}$ & $\begin{array}{l}10.4736 \\
(2.4431)\end{array}$ \\
\hline$\kappa_{2}^{\mathbb{P}}$ & $\begin{array}{l}10.2813 \\
(2.6862)\end{array}$ & $\begin{array}{l}10.0342 \\
(3.1077)\end{array}$ & $\begin{array}{c}5.6355 \\
(1.8521)\end{array}$ & $\begin{array}{l}10.4991 \\
(4.1381)\end{array}$ & $\begin{array}{l}13.2951 \\
(3.5110)\end{array}$ & $\begin{array}{c}30.0000 \\
(14.4270)\end{array}$ & $\begin{array}{l}25.2783 \\
(7.2493)\end{array}$ \\
\hline$\kappa_{2}^{\mathbb{P}} \theta_{2}^{\mathbb{P}}$ & $\begin{array}{l}-70.2813 \\
(23.5931)\end{array}$ & $\begin{array}{l}-84.0000 \\
(29.8984)\end{array}$ & $\begin{array}{c}-47.2718 \\
(18.0753)\end{array}$ & $\begin{array}{l}-82.0000 \\
(35.3029)\end{array}$ & $\begin{array}{r}-128.3527 \\
(35.4439)\end{array}$ & $\begin{array}{c}-281.6250 \\
(140.6748)\end{array}$ & $\begin{array}{c}-248.0000 \\
(69.4638)\end{array}$ \\
\hline$\sigma_{M}$ & $\begin{array}{c}0.0008 \\
(0.0002)\end{array}$ & $\begin{array}{c}0.0011 \\
(0.0126)\end{array}$ & $\begin{array}{c}0.0011 \\
(0.0540)\end{array}$ & $\begin{array}{c}0.0014 \\
(0.0712)\end{array}$ & $\begin{array}{c}0.0017 \\
(0.0287)\end{array}$ & $\begin{array}{c}0.0018 \\
(0.1139)\end{array}$ & $\begin{array}{c}0.0026 \\
(0.1298)\end{array}$ \\
\hline$R^{\mathbb{Q}}$ & $\begin{array}{c}0.4943 \\
(0.0444)\end{array}$ & $\begin{array}{c}0.5721 \\
(0.0696)\end{array}$ & $\begin{array}{c}0.9411 \\
(0.0114)\end{array}$ & $\begin{array}{c}0.5675 \\
(0.1080)\end{array}$ & $\begin{array}{c}0.9472 \\
(0.0004)\end{array}$ & $\begin{array}{c}0.5957 \\
(0.0364)\end{array}$ & $\begin{array}{c}0.1696 \\
(0.0737)\end{array}$ \\
\hline LogLk & 8278.48 & 10463.40 & 10715.38 & 9931.51 & 7056.57 & 9384.24 & 8627.24 \\
\hline $\mathrm{N}$ & 140 & 192 & 192 & 192 & 140 & 192 & 192 \\
\hline
\end{tabular}

This table provides the maximum likelihood estimates for the model of Arakelyan et al. (2013). Standard errors are in parenthesis. Parameters $\kappa_{i}^{\mathbb{Q}}, \kappa_{i}^{\mathbb{Q}} \theta_{i}^{\mathbb{Q}}$ and $\sigma_{i}^{\mathbb{Q}}$, with $i=1,2$, denote the mean reversion, long-run mean and instantaneous volatility of default intensity $\left(\lambda^{\mathbb{Q}}\right)$ and illiquidity $\left(\gamma^{\mathbb{Q}}\right)$ processes under the $\mathbb{Q}$ probability measure. Analogously, $\kappa_{i}^{\mathbb{P}}, \kappa_{i}^{\mathbb{P}} \theta_{i}^{\mathbb{P}}$ and $\sigma_{i}^{\mathbb{P}}$ are the mean-reversion rate and long-run mean under the objective measure $\mathbb{P}$. $\sigma_{M}$ is the standard deviation of the residuals. The sample period covers January 2006 to May 2013, and the data frequency is weekly. 
Table 3: Principal components for illiquidity and default risk premia

\begin{tabular}{lrrrrrrrr}
\hline \multirow{3}{*}{ Country } & \multicolumn{3}{c}{ Illiquidity } & & \multicolumn{3}{c}{ Default } \\
\cline { 2 - 5 } \cline { 6 - 8 } & PC1 & PC2 & PC3 & & PC1 & PC2 & PC3 \\
\hline United States & -0.04 & 0.32 & 0.75 & & 0.30 & 0.48 & -0.37 \\
Japan & 0.44 & -0.34 & 0.32 & & 0.44 & -0.17 & -0.43 \\
Germany & 0.56 & 0.24 & 0.10 & & 0.48 & -0.09 & 0.03 \\
France & 0.40 & 0.52 & -0.06 & & 0.45 & -0.28 & 0.21 \\
United Kingdom & 0.31 & -0.46 & -0.22 & & 0.32 & 0.47 & -0.21 \\
Italy & 0.28 & 0.35 & -0.50 & & 0.41 & -0.30 & 0.40 \\
Russia & 0.39 & -0.34 & 0.16 & & 0.13 & 0.58 & 0.66 \\
\hline Explained variance (\%) & 36.57 & 20.02 & 15.47 & & 56.22 & 28.81 & 6.68 \\
\hline
\end{tabular}

This table provides the loading coefficients and explained variance for the illiquidity and default risk premia of the sovereign CDS under study. The sample period covers January 2006 to May 2013 , and the data frequency is bi-weekly. 
Table 4: Regressions for the illiquidity and default premia

\begin{tabular}{|c|c|c|c|c|}
\hline & \multicolumn{2}{|c|}{ Illiquidity premium } & \multicolumn{2}{|c|}{ Default premium } \\
\hline & $\Delta \mathrm{PC} 1$ & $\Delta \mathrm{PC} 2$ & $\Delta \mathrm{PC} 1$ & $\triangle \mathrm{PC} 2$ \\
\hline$\triangle \mathrm{PC} 1$ BidAsk1y & $.2361 * * *$ & $.3219 * * *$ & $.1517 * *$ & $.2056 * * *$ \\
\hline$\Delta \mathrm{PC} 1 \mathrm{Net}$ Vol & .3005 & $.6045^{*}$ & .0783 & -.1647 \\
\hline$\Delta \mathrm{PC} 1 \mathrm{Mkt}$ local & $-.2601 * *$ & .207 & $-.7372 * * *$ & .0067 \\
\hline$\Delta$ Vol Premium & -.0113 & -.0095 & $-.0281 * * *$ & .0031 \\
\hline$\Delta \mathrm{PC} 1$ Forex & -.0322 & -.2181 & $-.7965 * * *$ & -.3685 \\
\hline$\Delta$ Corporate BAA-AAA & 1.02 & -.962 & -.7215 & -.617 \\
\hline Cons. & .0169 & -.0419 & .0172 & -.0181 \\
\hline Obs. & 117 & 117 & 117 & 117 \\
\hline$R^{2}$-Adj & 0.1991 & 0.0736 & 0.4554 & 0.1409 \\
\hline
\end{tabular}

The significance of the variables is tested using White (1980) t-statistics. * for $\mathrm{p}<.10$, ** for $\mathrm{p}<.05$, and $* * *$ for $\mathrm{p}<.01$. 
Table 5: Granger causality tests

\begin{tabular}{|c|c|c|c|c|}
\hline Equation & Excluded & $\chi^{2}$ & df & Prob $>\chi^{2}$ \\
\hline \multicolumn{5}{|c|}{ Panel A.- Default and illiquidity } \\
\hline ILLIQ & DEF & 34.362 & 2 & 0.000 \\
\hline DEF & ILLIQ & 1.5121 & 2 & 0.470 \\
\hline \multicolumn{5}{|c|}{ Panel B.- Default, illiquidity, bid-ask, and stock market } \\
\hline DEF & ILLIQ & 2.6551 & 1 & 0.103 \\
\hline DEF & BIDASK & .75207 & 1 & 0.386 \\
\hline DEF & STOCK & .98236 & 1 & 0.322 \\
\hline ILLIQ & DEF & $7.9 \mathrm{e}-05$ & 1 & 0.993 \\
\hline ILLIQ & BIDASK & 11.783 & 1 & 0.001 \\
\hline ILLIQ & STOCK & 10.224 & 1 & 0.001 \\
\hline BIDASK & DEF & .38337 & 1 & 0.536 \\
\hline BIDASK & ILLIQ & 3.087 & 1 & 0.079 \\
\hline BIDASK & STOCK & 4.3337 & 1 & 0.037 \\
\hline STOCK & DEF & .86633 & 1 & 0.352 \\
\hline STOCK & ILLIQ & .93343 & 1 & 0.334 \\
\hline STOCK & BIDASK & 1.9924 & 1 & 0.158 \\
\hline
\end{tabular}

Granger causality tests for the bivariate VAR2 model with illiquidity and default risk premia, and for the multivariate VAR4 model with the illiquidity premium, the default premium, the bid-ask spread, and the stock market. The variables DEF, ILLIQ, BIDASK, and STOCK are the first principal components of the default risk premium, the illiquidity risk premium, the 1-year Bid-Ask spread, and the stock market, respectively. The lag of VAR2 and VAR4 models is selected according to the Schwarz Bayesian Information criterion. 
Table 6: Variance decomposition of the four-variable VAR model

\begin{tabular}{rrrrr}
\hline Step & STOCK & DEF & BIDASK & ILLIQ \\
\hline 1 & 8.33 & 2.58 & 10.18 & 78.91 \\
2 & 10.77 & 1.94 & 11.36 & 75.93 \\
4 & 14.81 & 1.22 & 12.80 & 71.17 \\
10 & 21.20 & 0.63 & 13.33 & 64.84 \\
15 & 23.09 & 0.53 & 12.62 & 63.76 \\
25 & 24.10 & 0.60 & 11.57 & 63.73 \\
50 & 24.26 & 1.11 & 10.95 & 63.68 \\
\hline
\end{tabular}

Error variance decomposition for the model VAR4. Each column displays the proportion of the variance of the error from forecasting $k$ steps ahead the response variable, due to the impulse in the variable indicated in the column heading. The results depend on the ordering of the variables. The order employed is STOCK, DEF, BIDASK, and ILLIQ. The sample period covers from January 2006 to May 2013, and the data frequency is bi-weekly. 
Figure 1: Bid-ask spreads
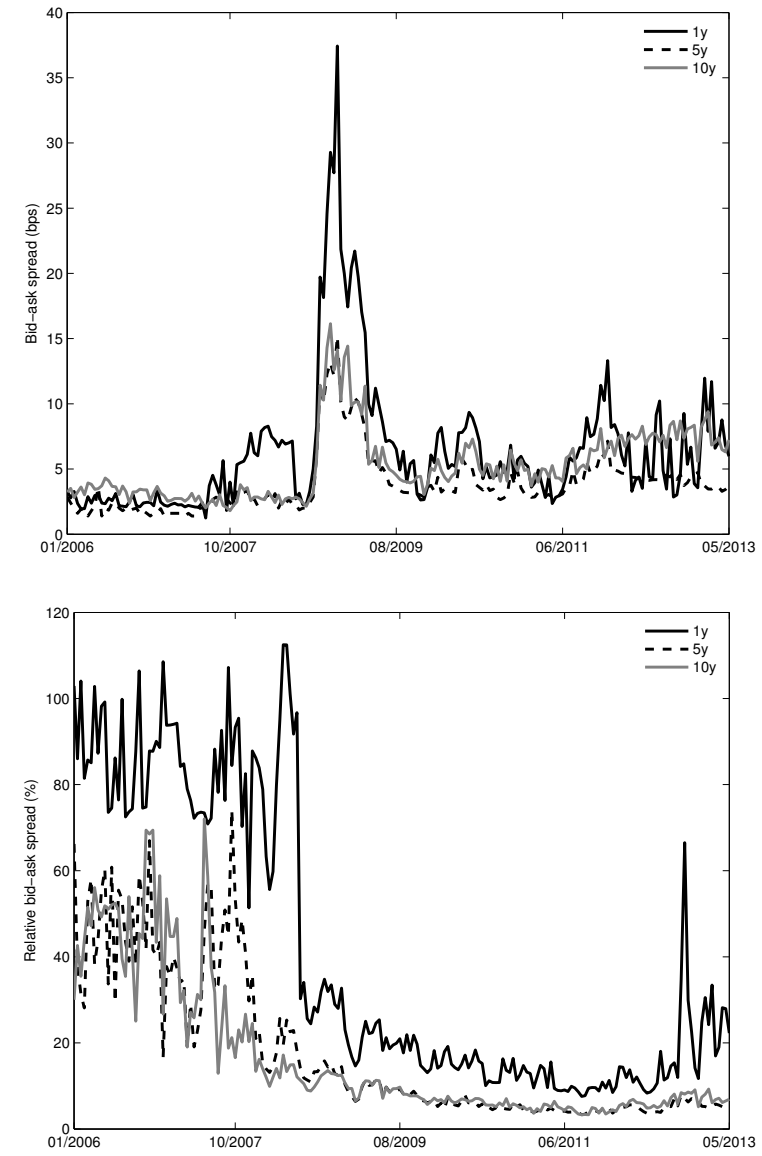

Absolute (upper) and relative (lower) cross-sectional average bid-ask spreads of sovereign CDS spreads. Maturities are 1-, 5- and 10-year. The data frequency is weekly and covers January 2006 to May 2013. 
Figure 2: Default and (relative) illiquidity discount processes
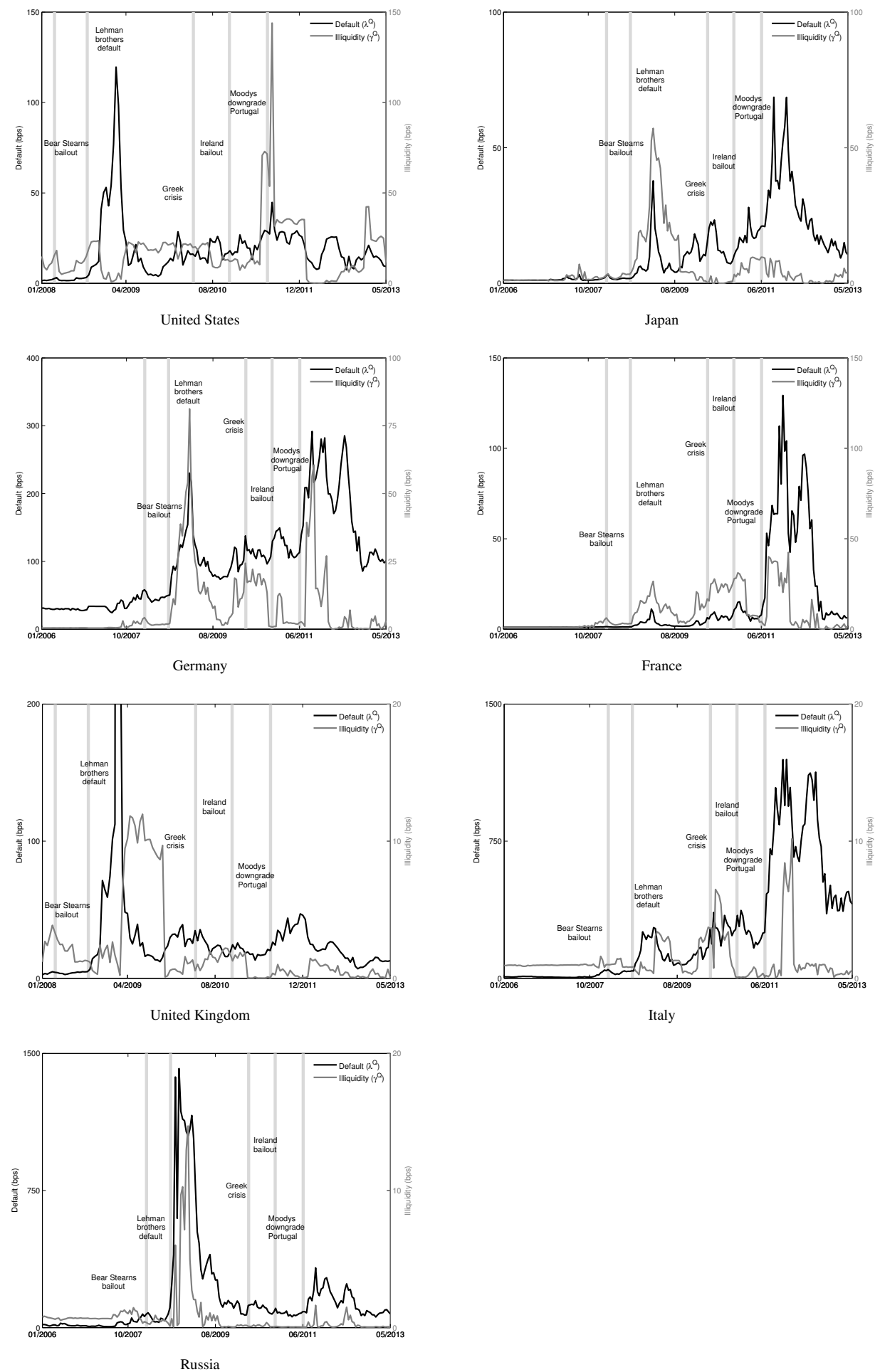

Risk-neutral default $\left(\lambda^{\mathbb{Q}}\right)$ and (relative) illiquidity $\left(\gamma^{\mathbb{Q}}\right)$ discount processes of sovereign CDS spreads. The data frequency is bi-weekly and covers January 2006 to May 2013. 
Figure 3: Default and (relative) illiquidity risk premium
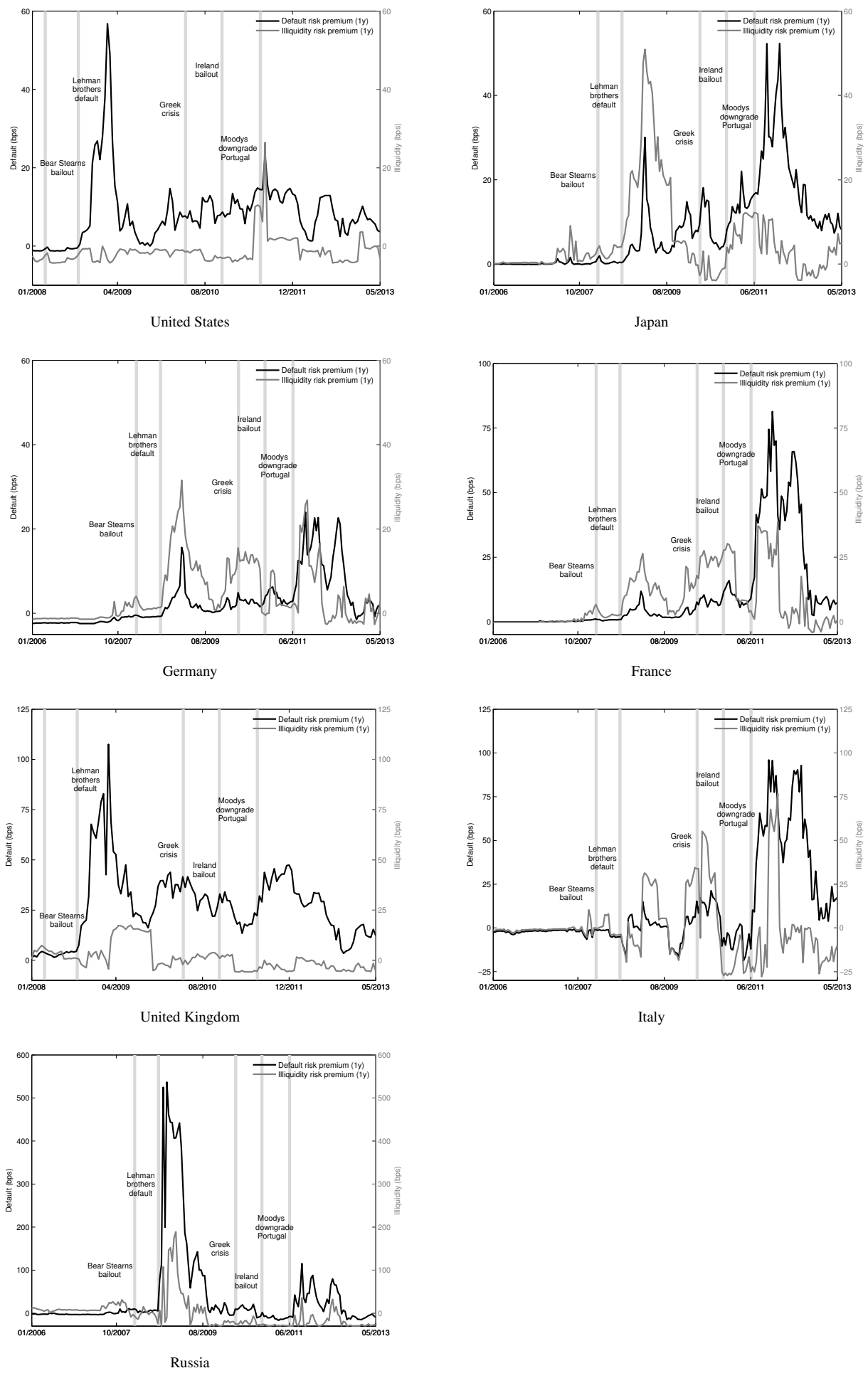

Default and (relative) illiquidity risk premia of sovereign CDS spreads. The data frequency is bi-weekly and covers January 2006 to May 2013. 
Figure 4: Impulse-response analysis

Panel A: VAR2 model

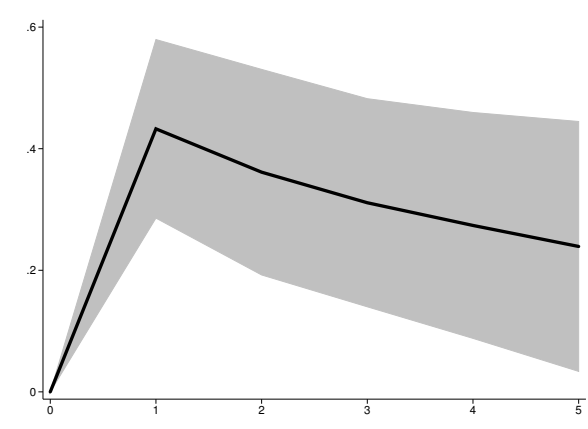

Shock in DEF and response in ILLIQ

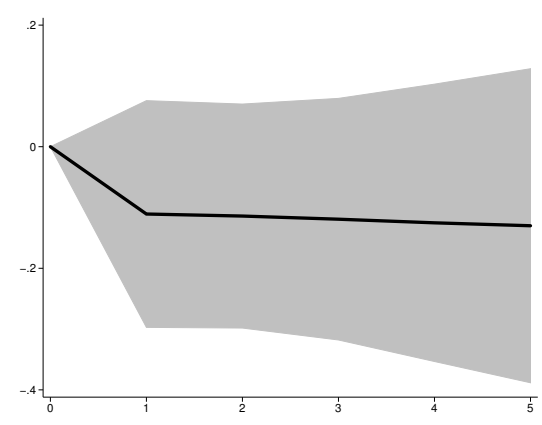

Shock in ILLIQ and response in DEF

Panel B: VAR4 model

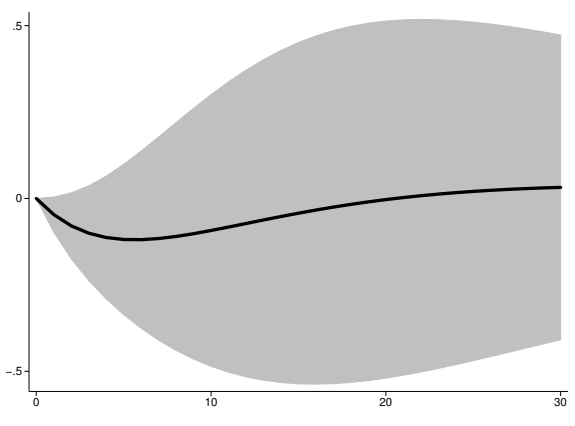

Shock in DEF and response in ILLIQ

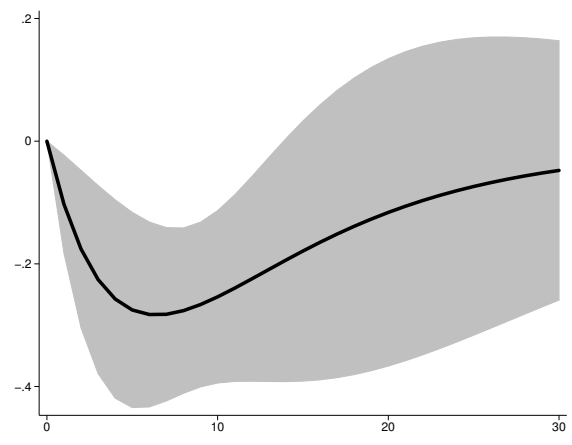

Shock in STOCK and response in ILLIQ

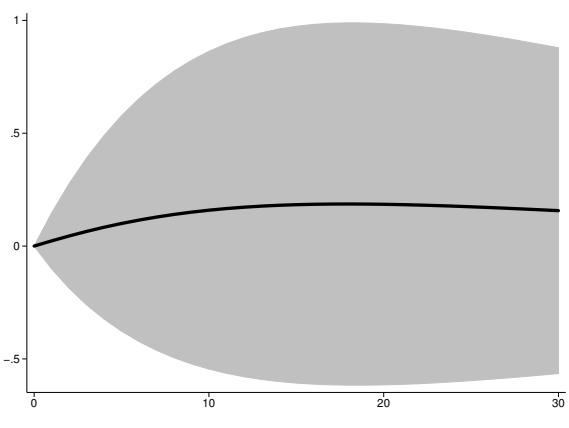

Shock in ILLIQ and response in DEF

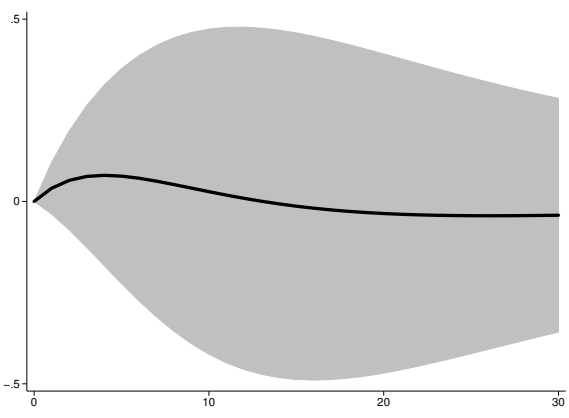

Shock in BIDASK spread and response in ILLIQ

Impulse-response figures for the aggregate illiquidity and default risk premia. Upper (lower) graphs correspond to the VAR2 model (VAR4 model). The shaded area represents the $95 \%$ confidence interval. The data frequency is bi-weekly and covers January 2006 to May 2013. 